\title{
ANALISIS FINANSIAL UNTUK KELAYAKAN USAHA UD. PRIMA BAKERY
}

\author{
Sajidil (1,Dyah Puspitasari Sunaryo Putri (2,dan Dadang Kurnia(3 \\ Universitas Pamulang \\ Wafasajidil7@gmail.com
}

\begin{abstract}
ABSTRAK
Penelitian ini bertujuan untuk melakukan studi kelayakan usaha yang ditinjau dari aspek finansial pada UD. Prima Bakery. Dengan mengunakan metode penelitian kualitatif deskriptif dalam melakukan analisis kelayakan finansial. Hasil perhitungan analisis finansial diperoleh hasil adalah Accounting Rate of Return 72\%, Payback Period 2.35 tahun, Net Present Value Rp. 64.443.000,Profitability Index 1.44, Net B/C Ratio 1.2, dan Break Even Point 477 \%. Dari hasil perhitungan diatas berdasarkan pertimbangan kriteria finansial menunjukkan bahwa kegiatan UD. Prima Bakery layak dijalankan.
\end{abstract}

Kata Kunci : Analisis Finansial, Kelayakan Usaha, Usaha Bakery

\section{PENDAHULUAN}

\section{A.LATAR BELAKANG MASALAH}

Usaha Mikro Kecil dan Menengah (UMKM) memberikan kontribusi terhadap perekonomian Indonesia, kontribusi yang diberikan oleh UMKM meningkat dari $57.84 \%$ menjadi $60.34 \%$. UMKM memiliki kontribusi terbesar dari usaha UMKM adalah industri ekonomi kreatif (Aryco, 2017).

Disisi lain, meskipun UMKM mempunyai peran penting serta memberikan kontribusi terhadap perekonomian, usaha UMKM memiliki kelemahan saat beroperasi. Salah satunya adalah pembukuan yang masih manual seringkali menghambat untuk bisa tumbuh dan scale up usahanya (Islamiyati, 2017).

Dari kelemahan pembukuan, dapat menimbulkan masalah bagi pelaku usaha pada saat mendirikan usaha produksi adalah menganalisis secara finansial usaha tersebut. Penentuan dan perhitungan biaya produksi, analisis untung rugi, titik impas dan waktu pengembalian modal.

UD. Prima Bakery adalah UMKM yang bergerak di bidang produk roti. Roti adalah produk makanan yang terbuat dari tepung terigu dan dicampur dengan gula serta pertambahan bahan makanan lain yang dipanggang menjadi produk dengan nilai tambah dan siap dikonsumsi.

UD. Prima Bakery belum pernah melakukan pembuatan laporan keuangan tahunan selama perusahaan berdiri. Sehingga belum bisa diketahui kelayakan usaha ini, serta tidak diketahui kapan modal usaha akan kembali dan berapa unit yang harus diproduksi agar modal usaha cepat kembali.

Berdasarkan penjelasan pada latar belakang, identifikasi masalah pada penelitian ini adalah penulis ingin mengetahui :

Bagaimana kelayakan usaha UD. Prima Bakery berdasarkan analisis finansial ?

\section{DASAR TEORI}

\section{A.Studi Kelayakan Bisnis}

Pengertian studi kelayakan bisnis adalah yang menyangkut berberapa aspek, salah satunya adalah aspek finansial. Hasil dari studi kelayakan digunakan untuk mengambil keputusan apakah proyek atau usaha dikerjakan atau ditunda dan bahkan tidak dijalankan (Kasmir dan Jakfar, 2012).

\section{B.Analisis Finansial untuk Kelayakan Usaha}

Analisis Finansial adalah aspek analisis yang bertujuan untuk menilai kelayakan suatu usaha apakah dijalankan atau tidak dijalankan dengan melihat beberapa indikator, yaitu : Accounting Rate of Return, Payback Period, Net Present Value, Profitability Index, Net B/C Ratio, Selain itu juga Break Even Point bermanfaat untuk mengetahui titik impas suatu produksi.

\section{C.Analisis Accounting Rate of Return}


Accounting Rate of Return didefinisikan rasio antara laba yang dihasilkan dengan nilai buku modal (Feenstra, D.W. and H. Wang : 2000).

\section{D.Analisis Payback Period}

Payback period adalah metode pengembalian menghitung jumlah tahun yang diperlukan untuk arus kas masuk agar sama dengan arus kas keluar (DeGarmo, E. Paul dkk, 1999 : 157).

Kriteria kelayakan analisis payback period adalah sebagai berikut:

- Usaha dikategorikan sebagai usaha yang layak apabila payback period modal lebih pendek daripada umur investasi usaha.

- Usaha dikategorikan sebagai usaha tidak layak apabila payback period modal lebih panjang daripada umur investasi usaha.

\section{E.Analisis Net Present Value dan Profitability Index}

Konsep Net Present Value dibangun dengan asumsi bahwa varian nilai sekarang dari manfaat dan biaya yang akan datang adalah nol (Basher, Syed Abul and David G. Robby, 2018).

Kriteria keputusan untuk mengetahui kelayakan usaha dengan menggunakan metode NPV adalah sebagai berikut :

- NPV > 0, Usaha layak diterima (menguntungkan)

- $\mathrm{NPV}<0$, Usaha tidak layak diterima (tidak menguntungkan)

Profitability Index merupakan salah satu cara yang dibutuhkan untuk menarik pemodal (Ullah, Hayat dkk: 2017). Profitability Index merupakan metode dengan membandingkan nilai sekarang dari penerimaan kas bersih di masa datang (proceeds) dan nilai sekarang dari investasi (outlays)

\section{F.Analisis Net B/C Ratio}

Analisis Benefit/Cost Ratio bertujuan membandingkan manfaat dan biaya dari beberapa alternative kebijakan yang berbeda. Diukur dalam satuan moneter di mana manfaat yang lebihbesar dari biaya disebut cost-effective (Casifo, Salvatore dan Carmelo D'Agostino, 2018).

Kriteria keputusan untuk mengetahui kelayakan usaha dengan analisis Net B/C Ratio adalah :

- Net $B / C$ Ratio $\geq 1$, maka usaha tersebut layak
- Net B/C Ratio < 1, maka usaha tersebut tidak layak

\section{G.Analisis Break Even Point}

Biaya tetap dan biaya variable dapat digunakan untuk mengindentifikasi break eveb point. Pada situasi ini, dimana perusahaan tidak rugi tapi juga tidak mencapai laba (Potkany, Marek dan Lucia Krajcirova, 2015).

Break even point adalah titik dimana jumlah produksi atau penjulan yang harus dilakukan agar biaya yang dikeluarkan dapat ditutupi kembali atau nilai dimana profit yang diterima adalah nol (Kusuma, Parama Tirta Wulandari Wening dan Nur Kartika Indah Mayasti, 2014)

Kriteria keputusan untuk mengetahui kelayakan usaha dengan analisis Break Even Point adalah :

- $\quad$ BEP > 100\%, maka usaha tersebut layak

- BEP < $100 \%$, maka usaha tersebut tidak layak

Berdasarkan diskripsi diatas maka penulis mengambarkan kerangka berpikir adalah sebagai berikut:

Gambar 2.1 Kerangka Berpikir

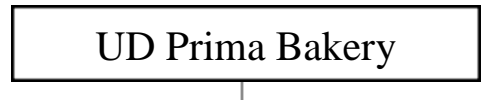

Aspek Finansial:

a. Accounting Rate of Return (ARR)

b. Payback Period (PP)

c. Net Present Value (NVP)

d. Profitability Index (PI) Net B/C Ratio (NBC)

e. Break Event Point (BEP)

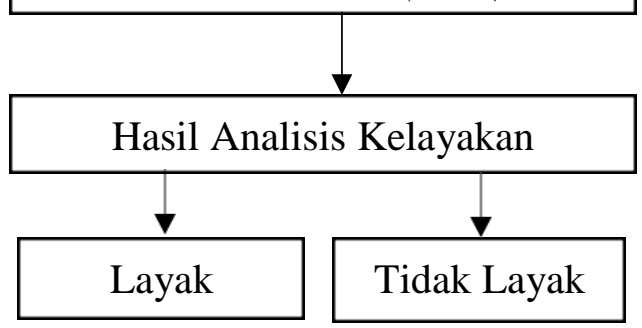

Sumber : Diolah Sendiri 


\section{METODOLOGI PENELITIAN}

Pada penelitian ini yaitu metode kualitatif deskriptif. Jenis data yang digunakan dalam penelitian ini terdiri dari data primer dan sekunder. Pengumpulan seluruh data yang diperlukan dalam penelitian ini dilakukan melalui metode dokumentasi.

Tahapan dalam melakukan analisis kelayakan finansial UD. Prima Bakery adalah sebagai berikut:

1. Estimasi Produksi

2. Estimasi Harga Roti

3. Penerimaan Per Tahun

4. Biaya Investasi

5. Biaya Operasional

6. Cash Flow

7. Perhitungan melalui Accounting Rate of Return, Payback Period, Net Present Value, Profitability Index, Net B/C Ratio dan Break Event Point (BEP).

8. Pemenuhan kriteria kelayakan finansial melalui Accounting Rate of Return, Payback Period, Net Present Value, Profitability Index , Net B/C Ratio dan Break Event Point (BEP).

Analisis kuantitatif ini disajikan dalam bentuk tabulasi yang mengelompokkan dan klasifikasi data agar mudah melakukan analisis. Pengelolaan data dilakukan dengan bantuan program Microsoft Excel.

\section{HASIL DAN PEMBAHASAN}

Perusahaan roti "UD Prima Bakery" yang berdiri di Desa Mojo, kecamatan Cluwak, Kabupaten Pati. Perusahaan ini berawal dari hobi salah seorang bapak yang bernama Sunardi dalam mengolah aneka macam makanan dari bahan baku sederhana dan bergizi tinggi dan bertujuan untuk konsumsi sendiri. Namun beliau melihat peluang untuk menjadikan keahlianya sebagai usaha karena banyak tetangga/saudara yang menyukai akan aneka macam roti hasil olahan tangannya.

\section{A.Estimasi Produksi}

Dari data penjualan tahun pertama maka estimasi hasil penjualan roti dalam jangka waktu 5 tahun adalah kenaikan 5\% setiap tahunnya dengan asumsi rata-rata kenaikan inflasi 5 tahun sebelumnya yang dapat dilihat pada tabel berikut:
Tabel 4.1 Jumlah Produksi Roti Dalam Jangka 5 Tahun

\begin{tabular}{|l|c|c|c|c|c|}
\hline \multirow{2}{*}{ Produksi } & \multicolumn{5}{|c|}{ Jumlah Unit Tahun ke } \\
\cline { 2 - 6 } & $\mathbf{1}$ & $\mathbf{2}$ & $\mathbf{3}$ & $\mathbf{4}$ & $\mathbf{5}$ \\
\hline $\begin{array}{l}\text { Roti } \\
\text { Pisang }\end{array}$ & 33.120 & 34.776 & 36.515 & 38.341 & 40.258 \\
\hline $\begin{array}{l}\text { Roti } \\
\text { Bluder }\end{array}$ & 16.836 & 17.678 & 18.562 & 19.490 & 20.465 \\
\hline $\begin{array}{l}\text { Roti } \\
\text { Jari }\end{array}$ & 21.252 & 22.315 & 23.431 & 24.603 & 25.833 \\
\hline $\begin{array}{l}\text { Roti } \\
\text { Cacah }\end{array}$ & 31.992 & 33.592 & 35.272 & 37.036 & 38.888 \\
\hline
\end{tabular}

(Sumber: UD Prima Bakery)

\section{B.Estimasi Harga Roti}

Harga untuk setiap roti berbeda karena disesuaikan dengan bahan baku yang digunakan dan ada juga yang sama. Berikut adalah harga produk roti pada UD. Prima Bakery:

Tabel 4.2 Harga Roti Dalam Jangka 5 Tahun

\begin{tabular}{|l|r|r|r|r|r|}
\hline \multirow{2}{*}{ Produksi } & \multicolumn{5}{|c|}{ Harga (Rp)/ Tahun ke } \\
\cline { 2 - 6 } & $\mathbf{1}$ & $\mathbf{2}$ & $\mathbf{3}$ & $\mathbf{4}$ & $\mathbf{5}$ \\
\hline Roti & 1.500, & 1.600 & 1.700, & 1.800, & $1.900,-$ \\
Pisang & - &,- & - & - & \\
\hline $\begin{array}{l}\text { Roti } \\
\text { Bluder }\end{array}$ & 2.500 & 2.600 & 2.750, & 2.900, & $3.000,-$ \\
\hline $\begin{array}{l}\text { Roti } \\
\text { Jari }\end{array}$ & 2.500, &,- & - & - & \\
\hline Roti & - &,- & - & - & $3.000,-$ \\
Cacah & 1.500, & 1.600 & 1.700, & 1.800, & $1.900,-$ \\
\hline
\end{tabular}

*Harga menyesuaikan kondisi lingkungan desa (Sumber: UD Prima Bakery)

\section{C.Penerimaan Pertahun}

Berdasarkan data produksi pada tabel 4.1 dan harga produk pada tabel 4.2, maka jumlah penerimaan pertahun adalah sebagai berikut:

Tabel 4.3 Penerimaan pertahun UD Prima Bakery

\begin{tabular}{|l|c|c|c|c|c|}
\hline \multirow{2}{*}{ Produksi } & \multicolumn{5}{|c|}{ Penerimaan Rp (dalam 000) } \\
\cline { 2 - 6 } & $\mathbf{1}$ & $\mathbf{2}$ & $\mathbf{3}$ & $\mathbf{4}$ & $\mathbf{5}$ \\
\hline Roti Pisang & 49.680 & 55.642 & 69.014 & 69.013 & 76.490 \\
\hline Roti Bluder & 42.090 & 45.962 & 51.046 & 56.521 & 61.395 \\
\hline Roti Jari & 53.130 & 58.018 & 64.435 & 71.348 & 77.499 \\
\hline Roti Cacah & 47.998 & 53.747 & 59.962 & 66.665 & 73.887 \\
\hline Total & 192.888 & 213.368 & 237.519 & 263.548 & 289.271 \\
\hline
\end{tabular}

(Sumber: UD Prima Bakery) 


\section{D.Biaya Investasi}

Biaya investasi adalah biaya yang dikeluarkan pada tahun pertama usaha. Biaya- biaya tersebut dikeluarkan unuk memenuhi kebutuhan sarana dan prasarana yang dibutuhkan untuk menjalankan usaha. Rincian biaya investasi yang dikeluarkan pada usaha ini adalah sebagai berikut:

Tabel 4.4 Biaya Investasi Usaha Pembuatan

\begin{tabular}{|l|c|l|r|r|}
\hline $\begin{array}{c}\text { Komponen } \\
\text { Biaya }\end{array}$ & Jumlah & Satuan & $\begin{array}{c}\text { Harga Rp. } \\
\text { (dalam 000) }\end{array}$ & $\begin{array}{c}\text { Total Rp } \\
\text { (dalam } \\
\text { 000) }\end{array}$ \\
\hline Bangunan & 80 & $\mathrm{M}^{2}$ & 1.500 & \multicolumn{1}{c|}{120.000} \\
\hline Oven & 4 & Unit & 4.500 & 18.000 \\
\hline Kompor & 1 & Unit & 250 & 250 \\
\hline Tabung gas & 3 & Unit & 100 & 300 \\
\hline Loyang besar & 100 & Unit & 13 & 1.300 \\
\hline Loyang kecil & 20 & Unit & 10 & 200 \\
\hline Wajan & 1 & Unit & 200 & 200 \\
\hline Susuk & 1 & Unit & 15 & 15 \\
\hline Meja produksi & 1 & Unit & 500 & 500 \\
\hline Meja adonan & 1 & Unit & 6.000 & 6.000 \\
\hline $\begin{array}{l}\text { Basket/ tempat } \\
\text { roti }\end{array}$ & 15 & Unit & 50 & 750 \\
\hline Timbangan & 1 & Unit & 150 & 150 \\
\hline \multicolumn{2}{|r|}{} & Total & 147.665 \\
\hline
\end{tabular}

(Sumber: UD Prima Bakery)

\section{E.Biaya Operasional}

Biaya operasional adalah biaya yang dikeluarkan agar telaksananya kegiatan produksi usaha tersebut. Biaya tersebut meliputi biaya tetap dan biaya variable.

a. Biaya tetap

Biaya tetap yang dikeluarkan oleh UD. Prima Bakery selama 1 tahun adalah sebagai berikut:

Tabel 4.5 Rincian Biaya Tetap

\begin{tabular}{|c|c|c|c|c|c|}
\hline & \multicolumn{5}{|c|}{ Biaya (Rp)/ Tahun ke (dalam 000) } \\
\hline & $\mathbf{t}$ & 2 & 3 & 4 & 5 \\
\hline Listrik & -600 & 630 & 662 & 695 & 729 \\
\hline Keamanan & 60 & 63 & 66 & 69 & 73 \\
\hline $\begin{array}{l}\text { Penyusutan } \\
\text { aset }\end{array}$ & $1 \underline{4} .867$ & 14.867 & 14.867 & 14.867 & 14.867 \\
\hline Total & 15.527 & 15.560 & 15.594 & 15.631 & 15.669 \\
\hline
\end{tabular}

*pemakaian listrik untuk lampu dan mesin adonan

(Sumber: UD Prima Bakery) b. Biaya variabel

Biaya variabel yang dikeluarkan oleh

UD. Prima Bakery adalah sebagai berikut:

Tabel 4.6 Rincian Biaya Variabel

\begin{tabular}{|l|c|c|c|c|c|}
\hline \multirow{2}{*}{} & \multicolumn{5}{|c|}{ Biaya (Rp)/ Tahun ke (dalam 000) } \\
\cline { 2 - 6 } & $\mathbf{1}$ & $\mathbf{2}$ & $\mathbf{3}$ & $\mathbf{4}$ & $\mathbf{5}$ \\
\hline $\begin{array}{l}\text { Bahan } \\
\text { Baku }\end{array}$ & 72.248 & 79.653 & 87.817 & 96.818 & 106.743 \\
\hline $\begin{array}{l}\text { Tenaga } \\
\text { Kerja } \\
\text { langsung }\end{array}$ & 62.400 & 68.640 & 75.504 & 83.054 & 91.360 \\
\hline & 134.648 & 148.293 & 163.321 & 179.872 & 198.103 \\
\hline
\end{tabular}

(Sumber: UD Prima Bakery)

\section{F.Cash Flow}

Cash Flow UD. Prima Bakery adalah sebagai berikut:

Tabel 4.7 Cash Flow UD. Prima Bakery

\begin{tabular}{|l|r|r|r|r|r|}
\hline & \multicolumn{5}{|c|}{ Cash Flow tahun ke /dalam (000) } \\
\cline { 2 - 6 } & $\mathbf{1}$ & $\mathbf{2}$ & \multicolumn{1}{c|}{$\mathbf{3}$} & $\mathbf{4}$ & $\mathbf{5}$ \\
\hline $\begin{array}{l}\text { Earning } \\
\text { Before } \\
\text { Interest Tax } \\
\text { (EBIT) }\end{array}$ & 42.713 & 49.515 & 58.603 & 68.045 & 75.480 \\
\hline \% TAx & 0 & 0 & 0 & 0 & 0 \\
\hline $\begin{array}{l}\text { Earning } \\
\text { AfterTaz } \\
\text { (EAT) }\end{array}$ & 42.713 & 49.515 & 58.603 & 68.03 & 75.480 \\
\hline $\begin{array}{l}\text { Penyusutan } \\
\text { Nilai Residu } \\
10 \%\end{array}$ & 14.867 & 14.867 & 14.867 & 14.867 & 14.867 \\
\hline Cash Flow & 57.580 & 64.382 & 73.470 & 82.912 & 91.853 \\
\hline
\end{tabular}

(Sumber: Diolah Sendiri)

Untuk tahun ke-1 residu bernilai 0 karena residu aka nada pada tahun ke-5, hal ini dikarenakan residu adalah nilai sisa dari penyusutan.

G.Perhitungan Accounting Rate of Return, Payback Period, Net Present Value, Net B/C Ratio dan Break Event Point (BEP)

Dalam mengetahui kelayakan usaha dilakukan perhitungan ARR,PP, NPV, BCR dan break even point. Hasil dari perhitungan kelayakan finansial UD. Prima Bakery adalah sebagai berikut:

\section{H.Analisis Accounting Rate of Return}

Tingkat bunga yang berlaku rata-rata adalah $13 \%$. Adapun ARR adalah : 


$$
\text { ARR }=\frac{\frac{\sum \text { EAT }}{n}}{\frac{\text { Nilai_Investasi+Residu }}{2}}
$$

Tabel 4.8 Perhitungan ARR

\begin{tabular}{|l|l|l|l|l|l|}
\hline \multirow{2}{*}{ Keterangan } & \multicolumn{4}{|l|}{ dalam (000) } \\
\cline { 2 - 6 } & $\mathbf{1}$ & $\mathbf{2}$ & $\mathbf{3}$ & $\mathbf{4}$ & $\mathbf{5}$ \\
\hline Nilai Investasi & 147.665 & & & & \\
\hline Residu 10\% & 14.767 & & & & \\
\hline EAT & 42.713 & 49.515 & 58.603 & 68.045 & 75.480 \\
\hline ARR $=72 \%$ & \multicolumn{5}{|l|}{} \\
\hline
\end{tabular}

(Sumber: Diolah Sendiri)

\section{I.Analisis Pay Back Period}

Waktu pengembalian modal yang diharapkan adalah 5 tahun. Perhitungan Pay Back Period adalah sebagai berikut:

Tabel 4.8 Perhitungan PP

Dalam Rp. $(00$

\begin{tabular}{|l|lr|}
\hline Proceeds (Nilai Investasi) & $\mathrm{Rp}$ & 147,665 \\
\hline Tahun ke-1 & $\mathrm{Rp}$ & 57,580 \\
\hline & $\mathrm{Rp}$ & 90,085 \\
\hline Tahun ke-2 & $\mathrm{Rp}$ & 64,382 \\
\hline & $\mathrm{Rp}$ & 25,703 \\
\hline
\end{tabular}

Karena alur kas (cash flow) tidak sama per tahunnya, maka rumus yang digunakan adalah :

$$
\mathrm{PP}=\text { Tahun Pengurang }+\left\{\left(\frac{\text { Nilai Sisa Uang Investasi }}{\text { Cash Flow Berikutaya }}\right) \times 1 \text { tahun }\right\}
$$

$$
\begin{aligned}
P P & \left.=2+\left\{\frac{25.703}{73.470}\right) \times 1 \text { tahun }\right\} \\
& =2+0,35=2,35 \text { Tahun }
\end{aligned}
$$

\section{J.Analisis Net B/C Ratio}

Perhitungan Net B/C ratio adalah sebagai berikut:

Tabel 4.9 Perhitungan $\mathrm{Net} B / \mathrm{C}$ ratio Rp. Dalam (000)

\begin{tabular}{l|r|r|r|r|}
\hline Cost & Benefit & $\begin{array}{c}\text { DF } \\
(20 \%)\end{array}$ & \multicolumn{1}{c|}{$\begin{array}{c}\text { PV } \\
\text { Cost }\end{array}$} & \multicolumn{1}{c|}{$\begin{array}{l}\text { PV } \\
\text { Benefit }\end{array}$} \\
\hline 150.175 & 192.888 & 0.83333 & 125.146 & 160.740 \\
\hline 163.853 & 213.363 & 0.69444 & 113.787 & 148.173 \\
\hline 178.915 & 237.519 & 0.57870 & 103.539 & 137.453 \\
\hline 195.503 & 263.548 & 0.48225 & 94.282 & 127.097 \\
\hline 213.772 & 289.271 & 0.40188 & 85.910 & 116.252 \\
\hline & Total & 522.664 & 689.714 \\
\hline
\end{tabular}

$$
\begin{aligned}
& \text { Net } B / C=\frac{\text { Pv Benefit }}{\operatorname{Pv} \text { Cost }} \\
& =689.714 / 522.664 \\
& =1.32
\end{aligned}
$$

Karena alur kas (cash flow) tidak sama per tahunnya, maka rumus yang digunakan adalah :

\section{K.Analisis Break Even Point}

Perhitungan Break Even Point adalah sebagai berikut:

Tabel 4.10 Elemen Perhitungan BEP Rp. Dalam (000)

\begin{tabular}{|c|c|c|c|}
\hline Th & $\begin{array}{c}\text { TFC } \\
\text { Rp }\end{array}$ & $\begin{array}{c}\text { TVC } \\
\text { Rp }\end{array}$ & $\begin{array}{c}\text { Net Sales } \\
\text { Rp }\end{array}$ \\
\hline 1 & 15.527 & 134.648 & 192.888 \\
\hline 2 & 15.560 & 148.293 & 213.368 \\
\hline 3 & 15.594 & 163.321 & 237.518 \\
\hline 4 & 15.631 & 179.872 & 263.548 \\
\hline 5 & 15.669 & 198.103 & 289.271 \\
\hline
\end{tabular}


Tabel 4.11 Perhitungan BEP

\begin{tabular}{|l|r|r|}
\hline Tahun & $\begin{array}{c}\text { BEP Keseluruhan } \\
\text { Rp. }\end{array}$ & $\begin{array}{c}\text { Presentasi BEP } \\
\text { Keseluruhan }\end{array}$ \\
\hline 1 & 51.424 & $375 \%$ \\
\hline 2 & 51.017 & $418 \%$ \\
\hline 3 & 49.920 & $476 \%$ \\
\hline 4 & 49.230 & $535 \%$ \\
\hline 5 & 49.716 & $582 \%$ \\
\hline Rata-rata & 50.261 & $477 \%$ \\
\hline
\end{tabular}

(Sumber: Diolah Sendiri)

\section{L.Analisis Net Present Value dan Profitability Index} berikut:

Perhitungan NPV dan PI adalah sebagai

Tabel 4.12 Perhitungan NPV dan PI

\begin{tabular}{|c|c|c|c|c|c|}
\hline Tahun & DF (20\%) & \multicolumn{2}{|c|}{ Proceeds (Rp) } & \multicolumn{2}{|c|}{ PV of Proceeds (Rp) } \\
\hline 1 & 0.8333 & $\mathrm{Rp}$ & 57,580 & $\mathrm{Rp}$ & 47,983 \\
\hline 2 & 0.6944 & $\mathrm{Rp}$ & 64,382 & $\mathrm{Rp}$ & 44,710 \\
\hline 3 & 0.5787 & $\mathrm{Rp}$ & 73,470 & $\mathrm{Rp}$ & 42,517 \\
\hline 4 & 0.4823 & $\mathrm{Rp}$ & 82,912 & $\mathrm{Rp}$ & 39,985 \\
\hline 5 & 0.4019 & $\mathrm{Rp}$ & 91,853 & $\mathrm{Rp}$ & 36,914 \\
\hline \multicolumn{4}{|c|}{ Total PV dari proceeds } & $\mathrm{Rp}$ & 212,108 \\
\hline \multicolumn{4}{|c|}{ Total PV dari outlays } & $\mathrm{Rp}$ & 147,665 \\
\hline \multicolumn{4}{|c|}{ Net Present Value (NPV) } & $\mathrm{Rp}$ & 64,443 \\
\hline \multicolumn{4}{|c|}{ Probability Index (PI) } & & 1.44 \\
\hline
\end{tabular}

(Sumber: Diolah Sendiri)

M.Pemenuhan Kriteria Kelayakan Accounting Rate of Return, Payback Period, Net B/C Ratio, Break Event Point (BEP) dan Net Present Value

Berdasarkan perhitungan Accounting Rate of Return, Payback Period, Net B/C Ratio, Break Event Point (BEP) dan Net Present Value. Maka dihasilkan kriteria kelayakan adalah sebagaimana Tabel. 4.12.

Tabel 4.12 Kriteria Kelayakan Finansial UD. Prima Bakery

\begin{tabular}{|l|l|l|c|}
\hline $\begin{array}{l}\text { N } \\
\mathbf{o}\end{array}$ & \multicolumn{1}{|c|}{$\begin{array}{c}\text { Kriteria } \\
\text { Kelayakan }\end{array}$} & Kelayakan & $\begin{array}{c}\text { Keteran } \\
\text { gan }\end{array}$ \\
\hline 1 & ARR & ARR $>13 \%$ & $72 \%$ \\
\hline 2 & Payback Period & $\begin{array}{l}\text { PP<Jangka waktu } \\
(5 \\
\text { tahun })\end{array}$ & 2.35 th \\
\hline 3 & NPV & NPV $>0$ & 64.443 \\
\hline 4 & PI & Pl $>1$ & 1.44 \\
\hline 5 & Net B/C & Net B/C $>1$ & 1.2 \\
\hline 5 & BEP & BEP $>100 \%$ & $477 \%$ \\
\hline \multicolumn{2}{|l|}{ Keputusan } & layak \\
\hline
\end{tabular}

\section{KESIMPULAN}

Berdasarkan hasil penelitian diatas menghasilkan beberapa kesimpulan bahwa usaha UD. Prima Bakery berdasarkan analisis finansial adalah layak.

\section{DAFTAR PUSTAKA}

Aryco, Henry. 2017 Pentingnya Peran UMKM Bagi Perekonomian Indonesia.http://internetmarketing.co.id/peranumkm-bagi-perekonomian-indonesia/. Diakses 1 juni 2019

Basher, Syed Abul, and David G. Raboy. 2018. "The misuse of net present value in energy efficiency standards." Renewable and Sustainable Energy Reviews 96: 218-225.

Cafiso, S., \& D'Agostino, C. 2018. A stochastic approach to the benefit cost ratio analysis of safety treatments. Case Studies on Transport Policy.

DeGarmo, E.P. Ekonomi Teknik, Jilid 1. 1999. Jakarta, Indonesia : PT Prehallind

Feenstra, D.W. and H. Wang. 2000. Economic and Accounting Rates of Return, Research Report 00E42, University of Groningen,. Research Institute SOM.

Islamiyati, Neisi. 2017. 5 Permasalahan Utama yang Dihadapi Para Pelaku UMKM. https://www.jagoanhosting.com/blog/5permasalahan-utama-. yang-dihadapi-parapelaku-umkm/. Diakses 1 juni 2019

Kasmir, Jakfar. Studi Kelayakan Bisnis, Edisi Revisi. Jakarta : Kencana. 2012

Kusuma, P. T. W. W., \& Mayasti, N. K. I. (2014). Analisa kelayakan finansial pengembangan usaha produksi komoditas lokal: mie berbasis jagung. Agritech, 34(2), 194-202.

Newnan, Donald G, Ted G. Eschenbach, Jerome P. Lavelle. 2012. Engineering Economic Analisys. Oxford University Press

Potkany, M., \& Krajcirova, L. 2015. Quantification of the volume of products to achieve the breakeven point and desired profit in nonhomogeneous production. Procedia economics and finance, 26, 194-201.

Ullah, H., Kamal, I., Ali, A., \& Arshad, N. 2018. Investor focused placement and sizing of photovoltaic grid-connected systems in Pakistan. Renewable energy, 121, 460-47 
